University of New Hampshire

University of New Hampshire Scholars' Repository

7-26-2013

\title{
Arctic warming and your weather: Public belief in the connection
}

Lawrence C. Hamilton

University of New Hampshire, Durham, lawrence.hamilton@unh.edu

Mary D. Lemcke-Stampone

University of New Hampshire, Durham, mary.stampone@unh.edu

Follow this and additional works at: https://scholars.unh.edu/soc_facpub

Part of the Sociology Commons

\section{Comments}

This is the pre-peer reviewed version of the following article: Hamilton, L.C. \& M. Lemcke-Stampone. 2014. "Arctic

warming and your weather: Public beliefin the connection." International Journal of Climatology 34:1723-1728, which has been published in final form at https://dx.doi.org/10.1002/joc.3796. This article may be used for non-commercial purposes in accordance with Wiley Terms and Conditions for Self-Archiving.

\section{Recommended Citation}

Hamilton, L.C. \& M. Lemcke-Stampone. 2014. "Arctic warming and your weather: Public beliefin the connection." International Journal of Climatology 34:1723-1728. doi: 10.1002/joc.3796

This Article is brought to you for free and open access by the Sociology at University of New Hampshire Scholars' Repository. It has been accepted for inclusion in Sociology Scholarship by an authorized administrator of University of New Hampshire Scholars' Repository. For more information, please contact Scholarly.Communication@unh.edu. 
AUTHORS' DRAFT: Final version published in:

International Journal of Climatology (2014) 34:1723-1728. doi: 10.1002/joc.3796

\title{
ARCTIC WARMING AND YOUR WEATHER PUBLIC BELIEF IN THE CONNECTION
}

Lawrence C. Hamilton

Department of Sociology

University of New Hampshire
Mary Lemcke-Stampone

Department of Geography

University of New Hampshire

\begin{abstract}
Will Arctic warming affect mid-latitude weather? Many researchers think so, and have addressed this question through scientific articles and news media. Much of the public accepts such a connection as well. Across three New Hampshire surveys with more than 1,500 interviews, sixty percent of respondents say they think future Arctic warming would have major effects on their weather. Arctic/weather responses changed little after Superstorm Sandy brushed the region, but exhibit consistently strong partisan divisions that grow wider with education. Belief in an Arctic/weather connection also varies, in a nonlinear pattern, with the temperature anomaly around day of interview. Interviewed on unseasonably warm or cool days, respondents are more likely to think that Arctic warming would have major effects on their weather. This unscientific response seems to mirror the scientific discussion about extremes.
\end{abstract}

\section{INTRODUCTION}

Faster-than-linear decline in Arctic sea ice has become the most visible sign of Arctic warming (Stroeve et al. 2012). Sea ice area, extent and volume reached historical low points in September 2012 (Parkinson and Comiso 2013), breaking previous records set in 2007 or 2011. The steep downward trend has outpaced most scientific predictions, and fuels concern about global implications of Arctic warming and low sea ice conditions. Recent studies explore links between Arctic warming and mid-latitude winters or weather extremes (Screen and Simon 2013), including the dramatic experience of Superstorm Sandy (Greene et al. 2013). Decreased summer Arctic sea-ice extent has been linked to the development of highamplitude wave patterns during winter, increasing the frequency cold weather outbreaks across the midlatitudes (Overland and Wang 2010; Francis and Vavrus 2012; Tang et al. 2013). Observations also indicate a connection between amplified wave patterns driven by changes in Arctic climate and increased early winter snowfall, early snow melt, extreme summer heat and drought (Francis and Vavrus 2012; Greene and Monger 2012; Greene et al. 2013; Liu et al. 2012; Petoukhov et al. 2012).

News media reports have picked up on this research, quoting scientists and repeating their suggestions that mid-latitude weather is responding to Arctic change. Stories have made these connections at scales ranging from global or national (e.g., Conan and Harris 2011; Fogarty 2012; Gillis and Foster 2012) down to local (e.g., Eichorn 2013; Weber and Huttner 2013). Media discussion of possible Arctic effects spiked following Superstorm Sandy (e.g., Fischetti 2012; O'Hanlon 2012) and several new studies (e.g., Morin 2013 and Stone 2013 after Tang et al. 2013).

What does the general public make of this research and its media manifestations? On a series of recent surveys, we asked whether people think that future Arctic warming will affect the weather where they 
live. Almost all respondents say they think that such warming would have at least some effects. Partisan and educational differences emerge, however, on whether such effects would be major. That belief varies with daily temperature, as well.

This paper builds on earlier work that analyzed how individual characteristics and weather influence beliefs about the reality of anthropogenic climate change (Hamilton and Stampone 2013). The previous paper examined surveys conducted from spring 2010 through summer 2012. For this analysis of Arctic/weather beliefs, we employ more recent surveys conducted from fall 2012 through spring 2013.

\section{SURVEY AND WEATHER DATA}

The Granite State Poll, an omnibus survey by the University of New Hampshire, conducts telephone interviews with independent random samples of about 500 state residents four times each year. Through consistent sampling, interview protocols and probability weighting it seeks representative results from the state's adult population, which have been validated through election cycles (Scala and Smith 2007, 2011) and used in basic research (Hamilton 2011). The questions typically center on political issues, with a mix of other topics recently including science and climate change. Regarding climate beliefs and knowledge, Granite State Poll responses closely resemble those from a national survey that asked an overlapping set of questions (Hamilton 2012). The resemblance extends beyond response percentages to their multivariate relationships with other variables.

In fall 2012, winter 2013 and spring 2013, the poll carried a new question asking whether people think that Arctic warming would have major, minor or no effects on the weather where they live. Telephone interviewers rotated the order of response choices to avoid possible bias. There are no significant differences in Arctic/weather responses across the three surveys, which are pooled here for preliminary analysis (a decision we test again in later modeling). Question wording, response percentages, and codes used for modeling appear in Table 1. Sixty percent say they think that Arctic warming would have major effects on the weather where they live. Another 29 percent think it would have minor effects. Few think there would be no effects, or express no opinion. Table 1 also describes four background characteristics (age, gender, political party and education) known to predict general climate-related beliefs (McCright and Dunlap 2011; Hamilton 2012).

Following Keim et al. (2003) and Hamilton and Stampone (2013), we defined a statewide daily temperature index as the mean anomaly (relative to 1981-2010 normals for each station and date) among New Hampshire's five U.S. Historical Climatology Network (USHCN) weather stations (Menne 2009). Station temperature anomalies are well correlated $(r>0.85)$ across this small state despite its varied topography. One principal component explains 85 percent of the combined variance (eigenvalue $=.85$ ) over our 2010-2013 study period.

The mean of station temperature anomalies is used here to quantify the regional-scale weather pattern as warmer or colder compared to what would be expected on the survey date. The statewide mean of nonmissing USHCN daily temperature anomalies, temp1, is summarized in Table 1 for all days from January 1, 2010 through April 30, 2013. A second indicator, temp2, is the two-day average of temp1 (interview and previous day) for the 23 days in 2012 or 2013 on which the Arctic/weather question was asked. The state's variable weather, reflected here in temp 2 values ranging from -4.08 to $+10.56{ }^{\circ} \mathrm{C}$, improves statistical power for detecting temperature effects if they exist. A two-day window proves to 
have the strongest relation to Arctic/weather beliefs, consistent with findings of two previous studies (Egan and Mullin 2012; Hamilton and Stampone 2013).

Figure 1 charts the percent of respondents who think that Arctic warming would have major effects on their weather, broken down by respondent characteristics, two-day temperature and survey. Age and temp 2 are grouped for display in these bar charts, although kept in continuous form for later modeling. Differences by age group and gender are not statistically significant. Contrary to the hypothesis that Superstorm Sandy might have a detectable effect, there are no significant differences in survey responses before and after the late October 2012 storm. Although disastrous for New York and New Jersey, Sandy had milder impacts in New Hampshire. The lower right chart in Figure 1 shows at most a transient and nonsignificant bounce in the winter 2013 survey.

We do see significant associations between Arctic/weather belief, political party and education. Collegeeducated respondents more often think there would be major effects. Republicans are much less likely to agree, forming the only subgroup in Figure 1 for which "major effects" are not the majority view. A significant and apparently nonlinear pattern appears in the chart at lower left: belief in major Arctic/weather effects is higher when interviews take place on unseasonably warm or cool days. This response pattern seems analogous to scientific observations connecting Arctic warming and ice loss to weather extremes (Francis and Vavrus 2012) rather than unidirectional warming or cooling.

\section{BELIEF IN THE ARCTIC/WEATHER CONNECTION}

The nonlinear temperature effect and the education $\times$ party interaction expected from previous research were tested for spuriousness arising from differences among the three surveys by estimating a series of logit regression models. Such models, widely used in survey analysis, are well suited for categorical dependent variables like arcweath. They focus on the logit or log odds $(L)$ favoring a particular category of dependent variable $y$ :

$$
L_{i}=\ln \left[P\left(y_{i}=1\right) / P\left(y_{i}=0\right)\right]
$$

The log odds that $y$ equals 1 (e.g., arcweath = "major effects") for the $i$ th observation are modeled as a linear function of the independent variables $\left(x_{1 i}, x_{2 i}\right.$ etc. $)$ :

$$
L_{i}=\beta_{0}+\beta_{1} x_{1 i}+\beta_{2} x_{2 i}+\ldots+\beta_{m} x_{m i}
$$

Equivalently, by exponentiating [2] we obtain a multiplicative model for the odds $(O)$ favoring $y=1$ :

$$
O_{i}=\left[P\left(y_{i}=1\right) / P\left(y_{i}=0\right)\right]=\exp \left(\beta_{0}\right) \times \exp \left(\beta_{1} x_{1 i}\right) \times \exp \left(\beta_{2} x_{2 i}\right) \times \ldots \times \exp \left(\beta_{m} x_{m i}\right)
$$

Table 2 shows results from the logit regression of arcweath on respondent gender, age, party and education, with an education $\times$ party interaction and both linear (temp2) and quadratic (temp $2 \times$ temp 2$)$ terms for two-day temperature anomaly. The predictors also include two $\{0,1\}$ variables denoting the winter and spring surveys (against a fall baseline, so no fall indicator is needed). The coefficients column in Table 2 gives maximum-likelihood estimates of the $\beta$ parameters in [2]. The "odds" column gives odds ratios corresponding to $\exp (\beta)$ in [3], interpreted as multipliers for odds favoring belief that Arctic warming would have major effects. Odds ratios greater than 1.0 correspond to "positive" effects, and those below 1.0 to "negative" effects.

The multivariate analysis in Table 2 confirms that the significant bivariate relationships seen in Figure 1 (arcweath with party, education and temp2) are not spurious. Other studies have found that gender and age often predict general climate-change beliefs, but neither Figure 1 nor Table 2 detect gender or age 
effects on arcweath. Party and education, on the other hand, exhibit significant main and interaction effects. The main effects are interpreted as the effects of each variable when the other has a value of zero. Thus, the main effects of party (coefficients of -.801 and -1.258 for Independent and Republican, respectively) indicate that among people with some college or technical school (education $=0$ ), Independents and especially Republicans are less likely than Democrats to think that Arctic warming would have major effects on their weather. The main effect of education (.217) indicates that belief in an Arctic/weather connection increases with education among Democrats (who form the base category of party). The significant education $\times$ party interaction coefficients $(-.161$ and -.303$)$, however, alert us that effects of education are different among Independents and Republicans.

This education $\times$ party interaction is visualized as an adjusted marginal plot at left in Figure 2. Predicted probabilities and their 95 percent confidence bands (widest for Independents, the least numerous group) are calculated from the model in Table 2, adjusting for other predictors (Mitchell 2012). As noted, among Democrats belief that Arctic warming would have major effects rises with education. Among Republicans, however, this belief falls with education. As a result, the gap is widest among the besteducated partisans. For Independents, education seems to make little difference.

The quadratic term temp $2 \times t e m p 2$ is significant and positive, supporting the nonlinear effect suggested by Figure 1. Also consistent with Figure 1, we see no systematic differences across the three surveys. Thus, the observed temp2 effects cannot simply be seasonal, or explained by other broad events (such as Superstorm Sandy) that might have caused variation between surveys. The right-hand panel in Figure 2 visualizes the nonlinear effect of the two-day temperature anomaly, also based on Table 2. As anomalies pass about $5{ }^{\circ} \mathrm{C}$ above normal (the 1981-2010 average for that date), we see a rising probability of "major effects" response. Conversely, as they pass about $2{ }^{\circ} \mathrm{C}$ below normal, we see this probability rising as well.

Analyzing belief in anthropogenic climate change, Hamilton and Stampone (2013) found a temperaturexparty interaction, such that temperature effects (monotonic) occurred mainly amongst Independent rather than partisan voters. We tested for similar party differences in temperature effects by including a three-way temp $2 \times$ temp $2 \times$ party interaction in models for arcweath, but the three-way terms prove nonsignificant. A three-way graph analogous to the right panel Figure 2 would show three Ushaped curves that differ mainly in height: Democrats high, Republicans low, Independents in between. From this evidence, temperature anomalies exert roughly similar quadratic effects on respondents of each party. Alternative specifications using an ordinal version of arcweath, coding education and politics each with 7 categories instead of 3, or including additional background variables as predictors, all complicated the models without improving their fit. We also tested versions using temperature-anomaly windows ranging from one to seven days (the interview and six previous days). The quadratic term was significant for most of these windows, but a two-day window provided the best fit (judged by AIC or $F$ statistic), in agreement with previous studies (Egan and Mullin 2012; Hamilton and Stampone 2013).

\section{DISCUSSION}

Based on data representing just one U.S. state, our results invite replication. With that caveat, the finding that almost 90 percent of respondents think that Arctic warming would affect weather where they live, and 60 percent think such effects would be major, suggests a notable diffusion of scientific concern. Two analytical findings visualized in Figure 2 explore variation in these beliefs. 
An education $\times$ party interaction effect on Arctic/weather beliefs fits the pattern previously established for general climate-related views (studies cited in McCright 2011; more recently McCright and Dunlap 2011; Hamilton 2012; Hamilton and Stampone 2013) and for specifically polar topics (Hamilton 2008). Explanations of this information-elite polarization invoke biased assimilation (Lord et al 1979; Munro and Ditto 1997; Munro et al. 2002; Corner et al. 2012) or similar processes, through which people selectively acquire information that reinforces their pre-existing beliefs (Hamilton 2012). For example, they might selectively accept arguments consistent with their prejudices about climate change from among the contradictory public declarations that Sandy, and other weather events, are or are not related to Arctic warming. Better-educated individuals can more actively acquire scientific-sounding arguments that support ideology-linked beliefs on climate, increasing their polarization on this topic.

The right panel in Figure 2 highlights a less-resolved issue: the functional form of relationships linking perceptions to weather or climate. This form may be contingent on the indicators and specific survey questions used. The curvilinear relationship graphed in Figure 2 makes sense in terms of the arcweath question's internal logic, which implies unusual weather. Unusual weather has also been a theme of public discussion linking Arctic change to weather, including stories carried by local media not long before our surveys (e.g., Borenstein 2012; Conan and Harris 2012; Joyce 2012). Unusual weather ought to mean something stronger than temperatures a few degrees from normal, but experimenters have noticed that even trivial ambient conditions can influence responses to climate questions (Joireman et al. 2010; Lewandowski et al. 2012; Li et al. 2011; Risen and Critcher 2011). With that exaggeration in mind, the nonlinear temperature effect on Arctic/weather responses unscientifically mirrors scientific studies linking Arctic warming to mid-latitude weather extremes.

\section{ACKNOWLEDGMENTS}

Polar questions on the Granite State Poll have been supported by a grant from the National Science Foundation (PoLAR Climate Change Education Partnership DUE-1239783). Additional science questions are supported by another NSF grant (New Hampshire EPSCoR EPS-1101245), and by the Carsey Institute and Sustainability Institute at the University of New Hampshire. Sampling and data collection were done by the UNH Survey Center. The authors thank Jennifer Francis for suggestions on an earlier draft.

\section{REFERENCES}

Borenstein, S. 2012. "The polar opposite." Concord Monitor, October 11.

http://www.concordmonitor.com/news/2460213-95/ice-sea-antarctic-antarctica, accessed 5/15/2013.

Conan, N. and R. Harris. 2011. "Study links extreme weather and climate change." National Public Radio, February 17. http://www.npr.org/2011/02/17/133843546/Study-Links-Extreme-Weather-AndClimate-Change accessed 5/15/2013.

Conan, N. and R. Harris. 2012. "Arctic sea ice melt sets record.” New Hampshire Public Radio, September 11. http://nhpr.org/post/arctic-sea-ice-melt-sets-record, accessed 5/15/2013. 
Corner, A., L. Whitmarsh and D. Xenias. 2012. "Uncertainty, scepticism and attitudes towards climate change: Biased assimilation and attitude polarisation.” Climatic Change 114:463-478.

Egan, P.J. and M. Mullin. 2012. "Turning personal experience into political attitudes: The effect of local weather on Americans' perceptions about global warming.” Journal of Politics, 74(3):796-809.

Eichorn, D. 2013. "The warmer Arctic's relationship to central New York weather: Warm there, cold here." Syracuse Post-Standard, April 20.

http://www.syracuse.com/news/index.ssf/2013/04/the_arctics_relationship_to_ou.html accessed $5 / 15 / 2013$.

Fischetti, M. 2012. "Did climate change cause Hurricane Sandy?" Scientific American, October 30. http://blogs.scientificamerican.com/observations/2012/10/30/did-climate-change-cause-hurricane-sandy/ accessed 5/15/2013.

Fogarty, D. 2012. "Warmer summers cause colder winters, scientists say." Reuters, January 12. http://www.reuters.com/article/2012/01/13/us-climate-winter-idUSTRE80C0A520120113 accessed 5/15/2013.

Francis, J.A. and S.J. Vavrus. 2012. "Evidence linking Arctic amplification to extreme weather in mid-latitudes.” Geophysical Research Letters 39, doi:10.1029/2012GL051000, 2012

Gillis, J. and J.M. Foster. 2012. "Weather runs hot and cold, so scientists look to the ice." New York Times, March 28. http://www.nytimes.com/2012/03/29/science/earth/arctic-sea-ice-eyed-for-clues-toweather-extremes.html?_r=0 accessed 5/15/2013.

Greene, C.H., J.A. Francis and B.C. Monger. 2013. "Superstorm Sandy: A series of unfortunate events?" Oceanography 26(1):8-9, http://dx.doi.org/10.5670/oceanog.2013.11.

Greene, C.H. and B.C. Monger. 2012. "An Arctic wild card in the weather.” Oceanography 25(2):7-9.

Hamilton, L.C. 2008. "Who cares about polar regions? Results from a survey of U.S. public opinion." Arctic, Antarctic, and Alpine Research 40(4):671-678.

Hamilton, L.C. 2011. "Education, politics and opinions about climate change: Evidence for interaction effects." Climatic Change 104:231-242. doi: 10.1007/s10584-010-9957-8

Hamilton, L.C. 2012. "Did the Arctic ice recover? Demographics of true and false climate facts." Weather, Climate, and Society 4(4):236-249. doi: 10.1175/WCAS-D-12-00008.1

Hamilton, L.C. and M.D. Stampone. 2013. "Blowin' in the wind: Short-term weather and belief in anthropogenic climate change." Weather, Climate, and Society 5(2):112-119. doi: 10.1175/WCAS-D-1200048.1

Joireman, J., H.B. Truelove and B. Duell. 2010. Effect of outdoor temperature, heat primes and anchoring on belief in global warming. Journal of Environmental Psychology 30:358-367. 
Joyce, J. 2012. "New signs Arctic ice is melting at an alarming rate." WBZ-TV, September 20. http://boston.cbslocal.com/2011/09/20/new-signs-arctic-ice-is-melting-at-an-alarming-rate/, accessed 5/15/2013.

Kahan, D.M., H. Jenkins-Smith, and D. Braman. 2011. "Cultural cognition of scientific consensus." Journal of Risk Research 14(2):147-174.

Keim, B.D., A. Wilson, C.P. Wake and T. Huntington. 2003. "Are there spurious temperature Trends in the United States Climate Division Database?" Geophysical Research Letters 30(7):10.1029/2002GL016295.

Lewandowski, G.W. Jr., N.J. Ciarocco and E.L. Gately. 2012. "The effect of embodied temperature on perceptions of global warming." Current Psychology 31(3):318-324.

Li, Y., E.J. Johnson and L. Zaval. 2011. "Local warming: Daily temperature change influences belief in global warming." Psychological Science, 22(4):454-459.

Lord, C.G., L. Ross, and M.R. Lepper, 1979. "Biased assimilation and attitude polarization: The effects of prior theories on subsequently considered evidence." Journal of Personality and Social Psychology 37(11):2098-2109.

Liu, J. J.A. Curry, H. Wang, M. Song and R.M. Horton. 2012. "Impact of declining Arctic sea ice on winter snowfall.” Proceedings of the National Academy of Sciences 109(11):4074-4079.

McCright, A.M. 2011. "Political orientation moderates Americans' beliefs and concern about climate change." Climatic Change 104:243 - 253. doi: 10.1007/s10584-010-9946-y

McCright, A.M. and R.E. Dunlap. 2011. "The politicization of climate change: Political polarization in the American public's views of global warming." Sociological Quarterly 52, 155-194.

Menne, M.J., C.N. Williams Jr. and R.S. Vose. 2009. "The U.S. Historical Climatology Network monthly temperature data, version 2." Bulletin of the American Meteorological Society July:995-1007.

Mitchell, M.N. 2012. Interpreting and Visualizing Regression Models Using Stata. College Station, TX: Stata Press.

Morin, M. 2013. “Arctic ice loss may drive extreme weather patterns. Los Angeles Times, March 26. http://articles.latimes.com/2013/mar/26/science/la-sci-sn-arctic-ice-extreme-weather-20130326 accessed 5/15/2013.

Munro, G.D., and P.H. Ditto, 1997. "Biased assimilation, attitude polarization, and affect in reactions to stereotype-relevant scientific information." Personality and Social Psychology Bulletin 23(6):636-653.

Munro, G.D., P.H. Ditto, L.K. Lockhart, A. Fagerlin, M. Gready and E. Peterson. 2002. "Biased assimilation of sociopolitical arguments: Evaluating the 1996 U.S. presidential debate." Basic and Applied Social Psychology 24(1), 15-26. 
O’Hanlon, L. 2012. "How much climate change was in Hurricane Sandy"? Discovery News, November 2. http://news.discovery.com/earth/oceans/sandy-and-the-record-arctic-sea-ice-melt-121102.htm accessed $5 / 15 / 2013$.

Overland, J.E. and M. Wang. 2010. "Large-scale atmospheric circulation changes are associated with recent loss of Arctic sea ice." Tellus 62A:1-9.

Parkinson, C.L. and J.C. Comiso. 2013. "On the 2012 record low Arctic sea ice cover: Combined impact of preconditioning and an August storm." Geophysical Research Letters 40:1-6

Petoukhov, V., S. Rahmstorf, S. Petri and H.J. Schellnhuber. 2012. "Quasiresonant amplification of planetary waves and recent Northern Hemisphere weather extremes." Proceedings of the National Academy of Sciences 110, 14:5336-5341. doi/10.1073/pnas.1222000110

Risen, J.L. and C.R. Critcher. 2011. "Visceral fit: While in a visceral state, associated states of the world seem more likely." Journal of Personality and Social Psychology, 100(5):777- 793.

Scala, D. and A.E. Smith. 2007. "Does the tail wag the dog? Early presidential nomination polling in New Hampshire and the U. S.” American Review of Politics 28(Fall 2007/Winter 2008):401-424.

Scala, D. and A.E. Smith. 2011. "Riding the wave to a comeback: Charlie Bass vs. Ann Kuster in New Hampshire's 2nd Congressional District.” Pp. 139-159 in R. Adkins and D. Dulio (eds.), Cases in Congressional Campaigns: Riding the Wave. London: Routledge.

Screen, J.A. and I. Simmonds. 2013. "Exploring links between Arctic amplification and mid-latitude weather." Geophysical Research Letters 40:959-964.

Stone, D. 2013. "Is shrinking sea ice behind chilly spring?" National Geographic News, March 26. http://news.nationalgeographic.com/news/2013/03/130326-arctic-sea-ice-global-warming-scienceenvironment-spring/ accessed 5/15/2013.

Stroeve, J.C., M.C. Serreze, M.M. Holland, J.E. Kay, J. Malanik and A.P. Barrett. 2012. "The Arctic's rapidly shrinking sea ice cover: A research synthesis." Climatic Change 110:1005-1027.

Tang, Q., X. Zhang, X. Yang and J.A Francis. 2013. "Cold winter extremes in northern continents linked to Arctic sea ice loss." Environmental Research Letters 8, doi:10.1088/17489326/8/1/014036

Weber, T. and P. Huttner.. 2013. “'Arctic amplification' may have caused our prolonged winter.” Minnesota Public Radio, April 18. http://minnesota.publicradio.org/display/web/2013/04/18/daily-circuitclimate-cast-arctic-amplification accessed 5/15/2013. 
Table 1: Variable definitions. Survey responses shown with codes used for modeling, and with probability-weighted percentages or means $(n=1,678)$.

\section{Arctic/weather question}

Arcweath - If the Arctic region becomes warmer in the future, do you think that will have major effects, minor effects, or no effects on the weather where you live? (response order rotated)

Major effects on weather where I live (coded 1; 60\%)

Minor effects on weather where I live (coded 0;29\%)

No effects on weather where I live (coded $0 ; 5 \%$ )

DK/NA (coded 0; 6\%)

\section{Respondent background characteristics}

$\boldsymbol{A g e}$ - What is your current age? (mean 54 years, s.d. 17, range 18 to 96 years)

Gender - Male (coded 0; 49\%) or female (coded 1; 51\%)

Party - GENERALLY SPEAKING, do you usually think of yourself as a Republican, a Democrat, an Independent or what?

Democrat (coded 1 if Democrat, 0 otherwise; 43\%)

Independent (coded 1 if Independent, 0 otherwise; 19\%)

Republican (coded 1 if Republican, 0 otherwise; 38\%)

Education - What is the highest grade of education you completed and got credit for?

High school or less (coded $-1 ; 20 \%$ )

Technical school or some college (coded $0 ; 22 \%$ )

College graduate (coded $1 ; 34 \%$ )

Postgraduate work (coded 2; 23\%)

\section{Weather indicators}

Temp - New Hampshire USHCN stations mean daily temperature anomaly relative to $1981-$ 2010 normals. For all 1,216 days from January 2010 through April 2013, 1-day mean $1.28{ }^{\circ} \mathrm{C}$, s.d. $4.04{ }^{\circ} \mathrm{C}$, range -12.27 to $16{ }^{\circ} \mathrm{C}$.

Temp2 - New Hampshire USHCN stations mean temperature anomaly on interview and one previous day. For the 23 interview days in fall 2012, winter 2013 and spring 2013, 2-day mean $1.57{ }^{\circ} \mathrm{C}$, s.d. $3.66{ }^{\circ} \mathrm{C}$, range -4.08 to $10.56{ }^{\circ} \mathrm{C}$. 
Table 2: Predictors of belief that Arctic warming would have major effects on weather where you live. Results from probability-weighted logit regression (estimation sample $n$ $=1,551$ ).

\begin{tabular}{|c|c|c|c|c|}
\hline Predictor & Coef & SE & Odds & $p$ \\
\hline Gender (F) & -.142 & .125 & .868 & .257 \\
\hline Age & .003 & .004 & 1.003 & .456 \\
\hline \multicolumn{5}{|l|}{ Party } \\
\hline Democrat & $\ldots$ & $\ldots$ & $\ldots$ & $\ldots$ \\
\hline Independent & -.801 & .204 & .449 & .000 \\
\hline Republican & -1.258 & .165 & .284 & .000 \\
\hline Education & .217 & .099 & 1.242 & .029 \\
\hline \multicolumn{5}{|l|}{ Education $\times$ Party } \\
\hline Democrat & $\ldots$ & $\ldots$ & $\ldots$ & $\ldots$ \\
\hline Independent & -.161 & .167 & .852 & .335 \\
\hline Republican & -.303 & .135 & .738 & .025 \\
\hline Temp2 & -.050 & .037 & .951 & .174 \\
\hline Temp2 $\times$ temp2 & .012 & .004 & 1.012 & .005 \\
\hline \multicolumn{5}{|l|}{ Survey } \\
\hline fall 2012 & & $\ldots$ & $\ldots$ & \\
\hline $\begin{array}{l}\text { winter } 2013 \\
\text { spring } 2013\end{array}$ & $\begin{array}{l}-.028 \\
-136\end{array}$ & .167 & $\begin{array}{l}.973 \\
873\end{array}$ & $\begin{array}{r}.869 \\
461\end{array}$ \\
\hline & & & & \\
\hline constant & .923 & .287 & 2.517 & .001 \\
\hline
\end{tabular}


Arctic warming will have major effects on weather where you live
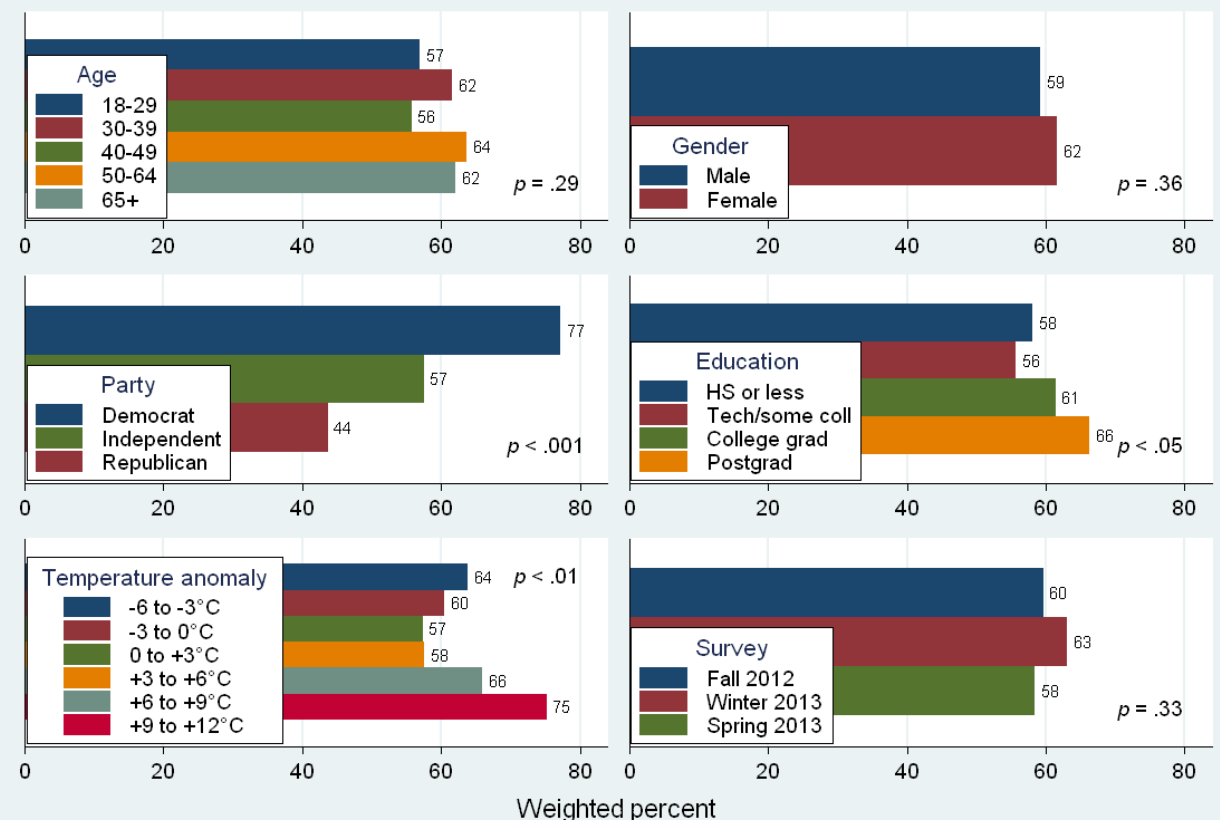

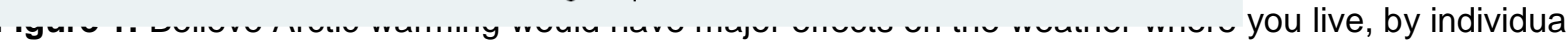
characteristics, temperature and survey. $P$ values are probabilities from design-based $F$ tests for null hypothesis of no association.

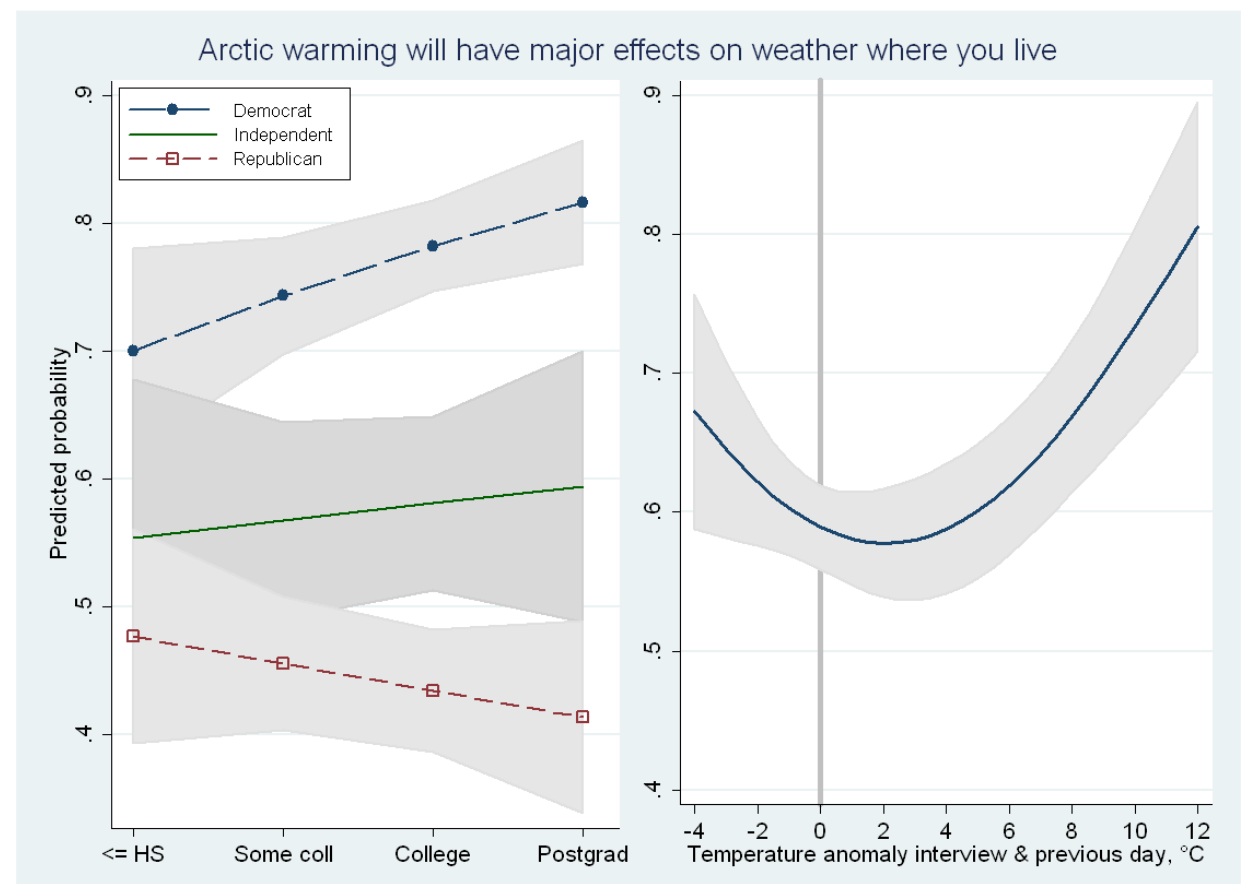

Figure 2: Predicted probability of "major effects" response as function of education and political party (left) and 2-day temperature anomaly (right), adjusting for other predictors in Table 2. 